\title{
Dorsal Cerebral Arterial Collaterals of the Rat
}

\author{
PETER COYLE ANI PENTTI T. JOKELAINEN \\ Department of Anatomy and Cell Biology, The University of Michigan \\ Medical School, Ann Arbor, Michigan 48109
}

\begin{abstract}
This study demonstrated that distal branches of the anterior cerebral artery (ACA) are joined by interarterial anastomoses to rami of the middle cerebral artery (MCA) in the normal Wistar rat. Arteries of 36- and 56-day-old animals were dilated with papaverine and injected with Vultex. Vultex arrived at corresponding ACA and MCA collaterals simultaneously as determined by microscopy through a skull window and photography. There were about $29 \mathrm{ACA}$ MCA junctions per hemisphere. Junction density was nearly constant along the frontal-occipital axis. The anastomoses were most numerous between 2 and $3 \mathrm{~mm}$ lateral to the midline and were less than $120 \mu \mathrm{m}$ in internal diameter. No significant difference was found between total numbers of junctions for right versus left hemispheres or between age groups. The most evident collateral pattern was characterized by two ACA end rami joining two MCA end branches to form a closed, diamond-shaped collateral unit. Considerations were given to alternate routes of blood flow into the MCA tissue field. We conclude abundant dorsal anastomoses exist in 36- and 56-day-old rats and are the prime potential source for ACA collateral supply to the MCA tissue field.
\end{abstract}

Interarterial anastomoses join branches of the three major cerebral arteries. These anastomoses are located in two regions. Ventrally, at the base of the brain joined arteries of the circle of Willis were studied extensively for vessel combinations in several species including rat (Brown, 1966; Greene, 1935; Zeman and Innes, 1963). Dorsally, distal branches of the middle cerebral artery (MCA) join rami of either the anterior (ACA) or posterior (PCA) cerebral artery at cortical arterial boundary zones in human (Beevor, 1907; Duret, 1874; Gillilan, 1974; Vander Eecken and Adams, 1953) and cat (Gillilan, 1976; Kamijyo and Garcia, 1975). For rat, little is known concerning even the presence of the distal anastomoses (Coyle, 1976). No literature was found indicating precise locations of the distal junctions and important pattern variations in the associated collaterals.

This investigation was undertaken to establish firmly the existence of dorsal arterial anastomoses in the normal Wistar rat. Selected information was obtained on regional locations, numbers, densities, and sizes of the anastomoses and patterns of the involved collateral arterioles. Such structural information is considered necessary to evaluate change, or detect lack of it, in these anastomoses and collaterals when attempts are made to increase the collateral circulation.

\section{MATERIALS AND METHODS}

\section{Animal preparations}

Six young (36-day-old) and six juvenile (56day-old) normal Wistar rats representing both sexes were anesthetized with ethyl ether before surgical exposure of the left external jugular vein (Greene, 1935). Papaverine hydrochloride $(40-50 \mathrm{mg} / \mathrm{kg}$ rat in sterile water) was injected intravenously to produce maximal vasodilation and minimize cerebrovascular resistance (Wang and Obrist, 1976). Undiluted Vultex, a white latex based compound (Chicago Latex Products No. 563) with pliable particles about 5-8 $\mu \mathrm{m}$ in diameter was warmed to $38^{\circ} \mathrm{C}$ and injected through an 18-gauge cannula secured in the ascending aorta with a ligature. Based upon many previous trials using this injection media and others (Coyle, 1975, 1978), with or without opening the right atrium, consistently better results were obtained if the atrium was left intact and the thoracic aorta was clamped at the diaphragm as done here.

\section{Visualization of vessels}

Skin and periosteum over the skull were reflected. Bone between the midline and tempo-

Received January 5, 19:2; accepted March 31. 1982 
ral ridge was thinned with a dental burr to permit microscopic observation of the collaterals during latex injection and to allow assessment of vessel filling. Thirty to 45 minutes after injection, the dorsal aspect of the skull was removed, dura mater was carefully reflected, and decapitation was performed. Tissues were fixed for several weeks in $10 \%$ neutral buffered formalin before brain removal. All brains were placed in a standard orientation for photography. Vascular prints were made 35 times real size for measurements compared with t-tests (Batson, 1963). Mean values \pm 1 standard error were graphed.

\section{Potential problems}

Rat pial surface arterioles do not crisscross one another. Medium ending abruptly in a vessel (Fig. 1A) indicates a more distal unfilled vessel segment. An uninterrupted latex-filled

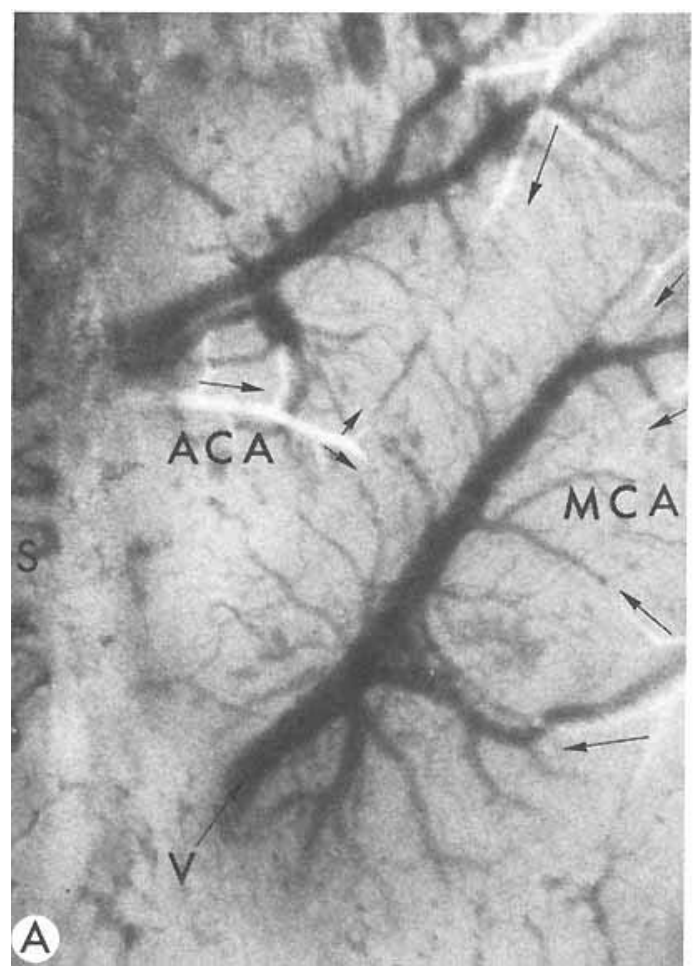

Fig. 1. Transcranial view of rat cerebral arterioles filling with Vultex. A and B) Same vascular field at same magnification but at slightly different times. A) Farly filling phase, B) later. Arrows indicate direction of flow from ACA and MCA sources. Note interarterial anastomoses (circles) of B arteriole is necessary to define its spatial course and provides sufficient evidence against unfilled arterioles crossing its path. Only specimens with uninterrupted patterns were utilized in this study.

Another potential problem is that the latex may not expand the vessel to its maximal diameter, particularly if the vessel is partially contracted. Papaverine was utilized to standardize all vessels at maximal dilation and to enhance conditions for filling. Because of media viscosity and the absence of vascular tone, aortic pressures meaningful for supply of blood (Berne and Levy, 1977) may be particularly misleading if applied during injection of Vultex. In using papaverine and microscopy in

\begin{tabular}{lc} 
& Abbreviations \\
\hline F, Frontal & S, Suture of skull \\
O, Occipital & V, Vein
\end{tabular}

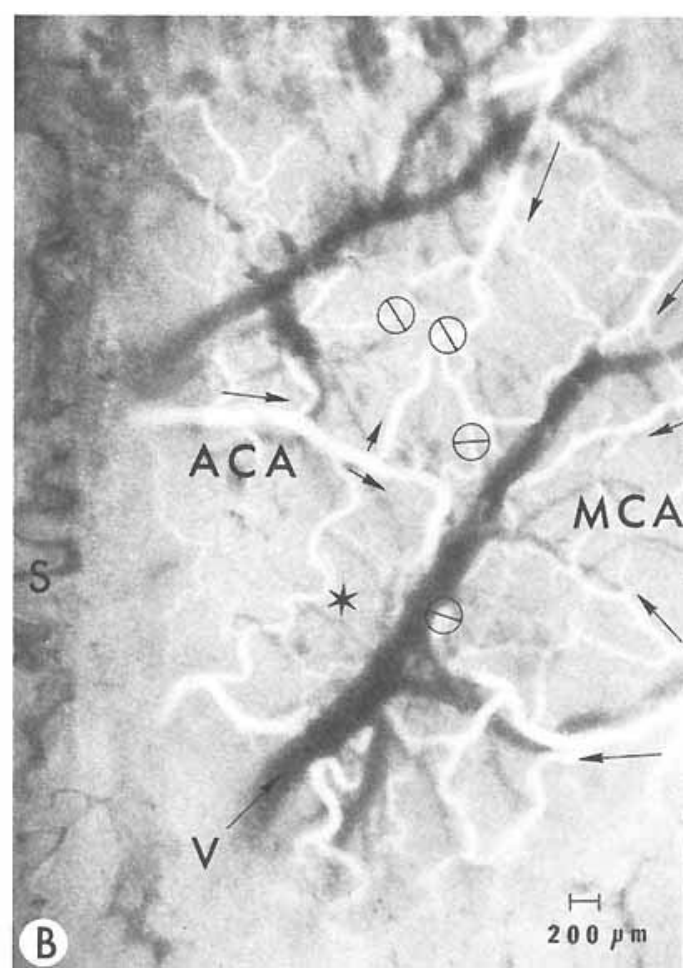

are located at positions about halfway between advancing fronts of latex in A. indicating simultaneous arrival at corresponding $\mathrm{ACA}$ and MCA collaterals. Stars at locations of intraarterial anastomoses. Midsagittal suture (S) of skull and cortical vein $(\mathrm{V})$ 
the control of vessel filling, rami as small as 15-20 micra internal diameter were observable.

\section{RESULTS}

\section{Passive filling of collaterals}

Media supply to two joined collaterals came simultaneously via ACA and MCA branches (Fig. 1). Rostral arterioles filled slightly before caudal ones located in the most distal portions of the ACA and MCA fields. The collaterals were observed to be the last vessels of the dorsal pial surface arterial tree to fill. When injection of the media was continued beyond the stage of collateral filling, one occasionally observed media in the dorsal veins (Fig. 2B). Four to six such veins characteristically drain blood from the dorsal MCA field (Fig. 1), then cross the ACA-MCA collateral zone (Fig. 1B) and drain the dorsal ACA field (Fig. 1A) before joining the superior sagittal sinus. The veins were easily identified for they crisscross the arterioles. In no case were arterial-venous junctions observed in the pial surface vasculature. Media in the veins came from within the cortex. The route within the cortex by which media entered the veins is unknown.

\section{Identification of anastomoses and patterns of collaterals}

Anastomoses were accurately localized by using vessel branch angles as determinants. Branch angles of two joined arterioles having MCA source for one and ACA source for the other characteristically face each other (Fig. 2). Because artrial blood normally flows into smaller vessels distal to a branch point, not combined into one larger vessel (unless flow direction is reversed), one can identify, on the basis of angle, if supply is from the ACA or MCA. Either the narrowest vessel width or the vessel distance one-half way between the two branch points was selected as the anastomosis point. The latter criterion was applied in cases where a clear-cut narrowing was not observed.

With origin at the branch point and termination at the anastomosis, a collateral is part of a pattern that is dependent upon the number of interarterial collaterals stemming from the branch point. A branch point was never observed to be the origin of more than two arterioles, one or both of which were interarterial collaterals. The most evident pattern was where both branches were end rami that joined a nearly mirror image set. The shape of the endto-end vascular complex is roughly that of a diamond (Fig. 2A, C). Common variations of
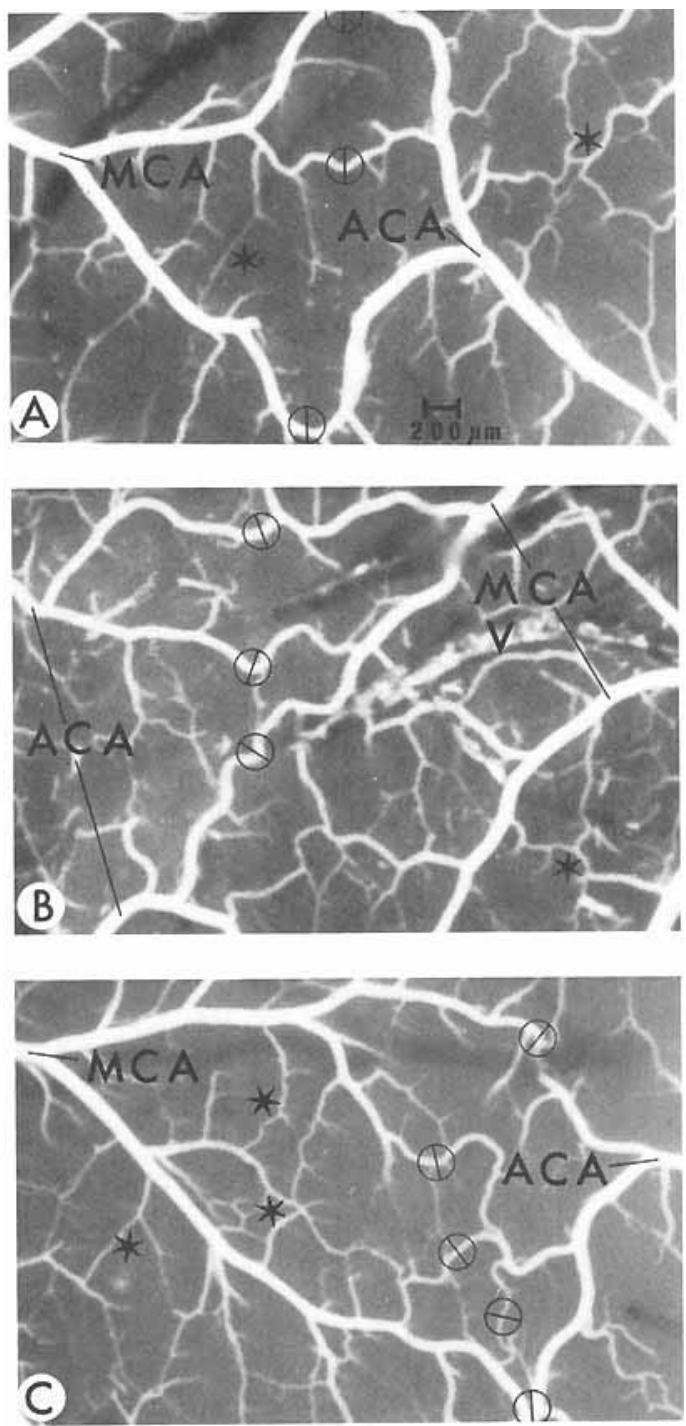

Fig. 2. Patterns of rat cerebral arterial collaterals made visible with Vultex. A and $\mathrm{C}$ demonstrate collateral units composed of end-to-end rami. Inter- and intraarterial anastomoses indicated by circles and stars respectively. Stars outside the unit's boundary in $\mathrm{A}$ and $\mathrm{C}$ indicate intraarterial anastomoses are not confined within a unit. $\mathrm{B}$ is a view of a vascular complex with end-to-side branches. Vein (V). $\times 15$

this collateral unit are vascular complexes with end-to-side or side-to-side configurations where only one end, or side branch of a bifurcation joins an interarterial collateral. Even within an area bounded by larger vessels form- 
ing a collateral unit, there were smaller diameter and shorter collaterals that were intraarterial and were by definition supplied by one (not two) major cerebral artery (Fig. 2A, C).

\section{Locations of interarterial anastomoses}

In rat, the unpaired ACA courses in the interhemispheric fissure with branches distributing bilaterally to the medial cortex on the dorsal aspect of the brain. The bilateral MCA is positioned laterally to supply the greatest portion of the neocortex. The ACA-MCA collaterals are located at the interface of distal branches of these two major supply vessels. Collateral units are present at the vascular border zone extending across frontal, parietal, and into occipital regions (Fig. 3). The parasagittal locations of the anastomoses vary from frontal to occipital fields. Junctional deviations from the midline are greatest near the frontal pole and least in the occipital region. Numerous branches of the posterior cerebral artery (unlabeled, Fig. 3) join rami of the MCA, but not the ACA, along a course roughly parallel to the transverse fissure separating occipital and cerebellar structures. The PCA-MCA anastomoses are intermediate in position between the dorsal ACA-MCA junctions and the ventral anastomoses of the arterial circle of Willis. Because of position, the majority of PCA-MCA collaterals may fill before those of the dorsal collaterals. Most PCA-MCA collaterals are not observable in our dorsal view preparation, so the filling pattern could not be seen.

\section{Measurements}

There were about 29 ACA-MCA anastomoses per hemisphere. No significant difference was noted between total numbers for right and left hemispheres nor between total numbers for the different age groups (Table 1).

The union sites were less than $120 \mu \mathrm{m}$ in internal diameter (Fig. 4A). On the average, most junctions were between 2 and $3 \mathrm{~mm}$ lateral to the midline (Fig. 4B), but as noted above, the positions varied from frontal to occipital regions. Distribution along the parasagittal axis was rather uniform with the average slightly less than two junctions/mm tissue (Fig. 4C). Fewer junctions were accumulated in the frontal pole bin. There was variation in brain length, and this may account for the aberrant frontal bin value.

\section{DISCUSSION \\ MCA field supply}

In rat, normal blood supply to the MCA tissue field is via the main stem of the MCA originating at the arterial circle of Willis (Brown, 1966; Greene, 1935; Zeman and Innes, 1963). This study demonstrated dorsal ACA-MCA anastomoses indicating the existence of alternate cerebral channels for blood supply to the MCA tissue field. Unlike in human data (vander Eecken and Adams, 1953), there are more but smaller diameter collaterals in rat. There is no evidence for a decreased density of ACAMCA junctions for one cortical region over

TABLE 1. Mean \pm standard error of rat ACA-MCA anastomoses by age, size. and hemisphere

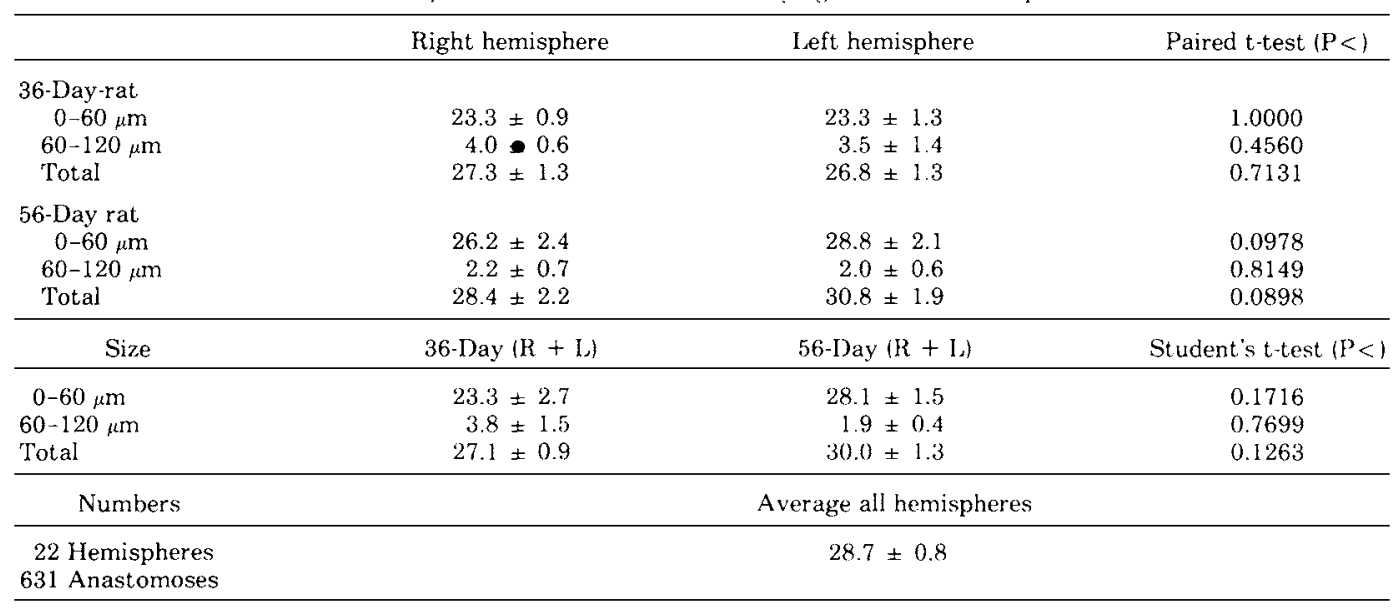




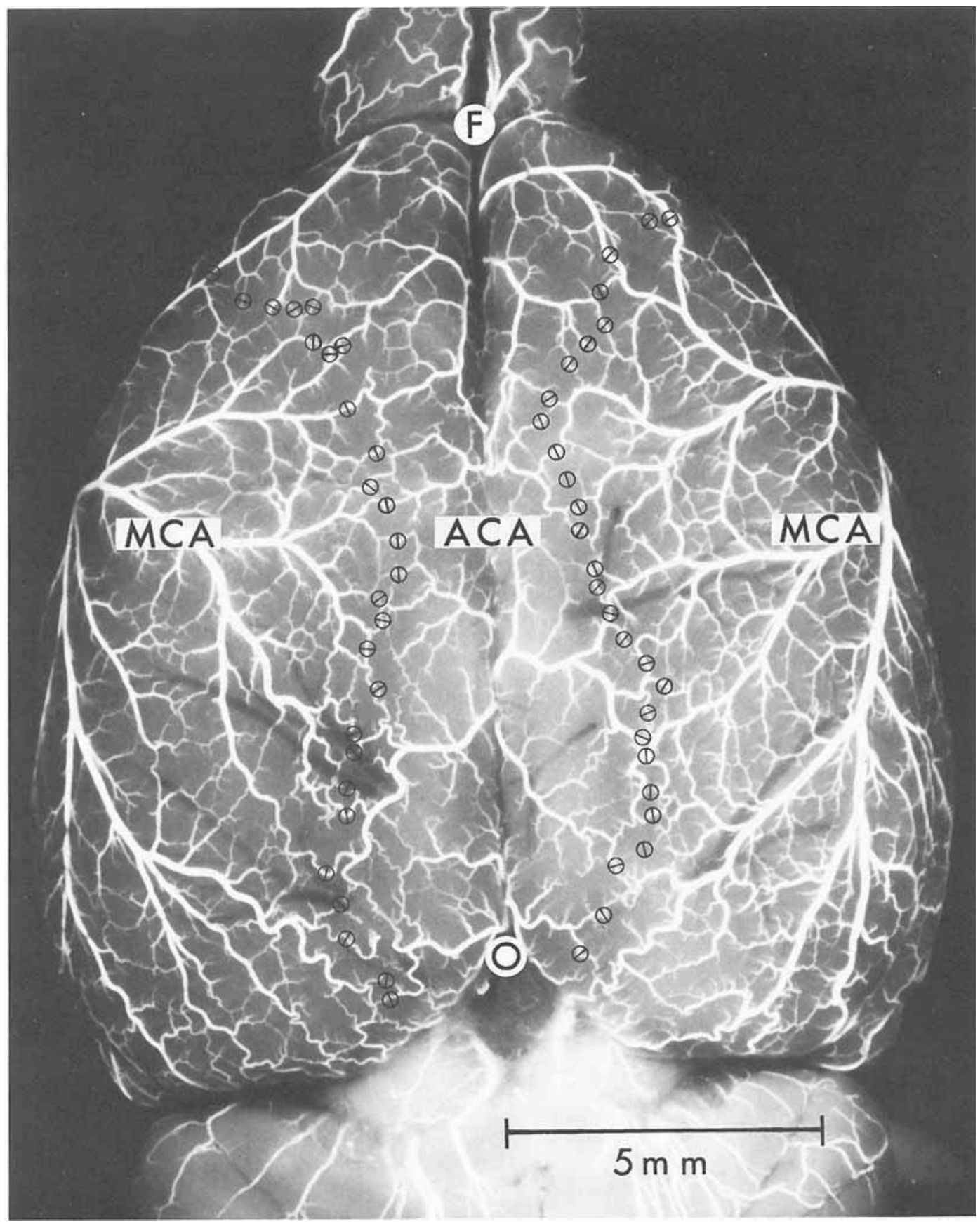

Fig. 3. Dorsal view of 56-day-old normal Wistar rat. Cerebral arteries injected with Vultex. Circles indicate locations of dorsal interarterial anastomoses. Note approximate bilateral symmetry of anastomoses and parasagittal distributions extending over frontal $(\mathrm{F})$, parietal, and into occipital $(O)$ regions. 


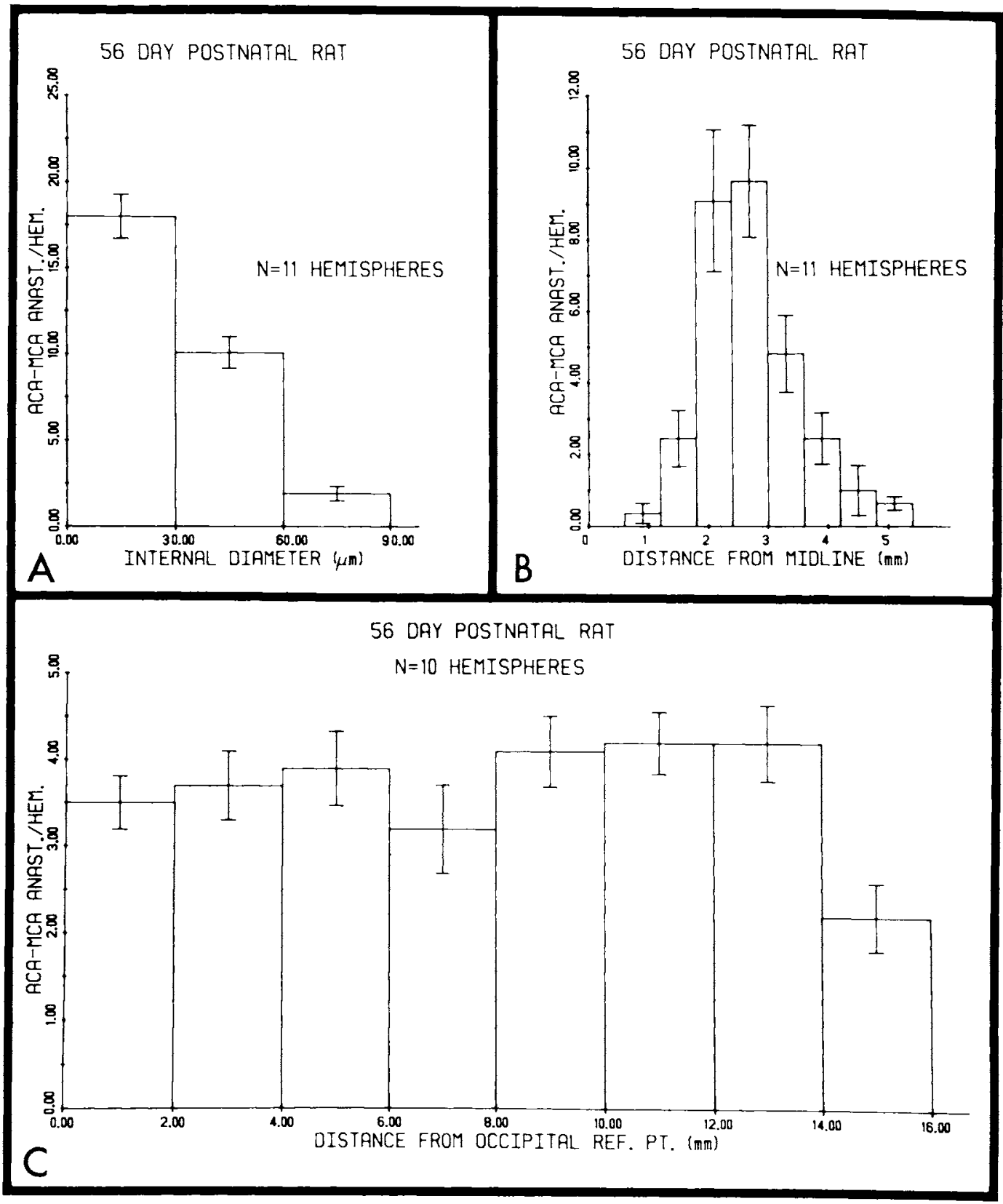

Fig. 4. Sizes and distribution profiles of the ACA-MCA anastomoses in 56-day-old rat.

another as in human (Gillilan, 1974) except possibly at the frontal pole.

Other cerebral sources for collateral flow to the MCA field are present in rat. Numerous PCA-MCA anastomoses exist. MCA unions with distal branches of the meningeal arteries were rare but were reported for human by Gillilan (1974) and cat by Kamijyo and Garcia (1975). Beevor (1907) found no evidence for intracortical collaterals in human, and concluded that cortical penetrating arteries do not anastomose with other arteries. Cortical pene- 
trating arterioles are smaller in caliber than surface conductors and collaterals in rat (Jokelainen et al., 1982), and intracortical collaterals, if present, in the arterial boundary zone would appear to have less collateral capacity compared to larger diameter surface arterioles. The choroidal arteries present in rat (Coyle, 1976; Zeman and Innes, 1963) and human supply the ventricular white matter. Anastomoses with cortical vessels were sought but none were observed (Van Den Bergh, 1969).

\section{Observations in vessel filling}

Microscopic observations made through the skull window during vessel filling indicated that the collaterals were the last dorsal surface arterioles to receive latex media. The passive resistance to latex flow must have been about the same in ACA and MCA systems as the media in both arteries arrived at corresponding collaterals simultaneously. Had the resistance to flow not been similar, then media would have arrived first at the collaterals of the artery with lower resistance, given that the vessel lengths are of similar value. Vessel filling under microscopic observation and experimental control also indicated latex in veins did not arrive via pial surface arterial-venous anastomoses. These could be difficult to exclude without observation of the filling because such junctions would easily be obscured, if present, in the pial surface network of vessels.

\section{Collaterals of 36- and 56-day-old rats}

No significant difference in total number of interarterial anastomoses between $36-$ and 56-day-old rats indicates all the junctions were formed before the 36th postnatal day. This is long after the last burst of intracortical vascular sprouting which occurs on day 14 (Rowan and Maxwell, 1981), and the adult intracortical vascular pattern is established at about day 21 (Craigie, 1955). An occlusion that results in an ACA-MCA collateral expansion could be undertaken on 36-day-old rats with assurance that, if significantly more or fewer vessels and anastomoses are present at 56 days, the change in number would not occur otherwise.

\section{Potential significance of the anastomoses}

Sudden occlusion of the MCA at its proximal end results in tissue ischemia and infarction in human (vander Eecken and Adams, 1953), monkey (Hudgins and Garcia, 1970; Molinari et al., 1974), and cat (Black et al., 1979;
Kamijyo and Garcia, 1975; O'Brien and Waltz, 1973). Because interarterial anastomoses were also demonstrated in human (Beevor, 1907; Duret, 1874; Gillilan, 1974; vander Eecken and Adams, 1953) and cat (Gillilan, 1976; Kamijyo and Garcia, 1975), one might suspect a similar lesion in rat even though existing anastomoses provide a link for collateral supply to the MCA tissue field. With slow occlusion of the MCA in three human cases, anastomotic vessels were larger and more numerous, and must have accomodated collateral flow accounting for smaller lesions than those after rapid occlusion (vander Eecken and Adams, 1953). Large collaterals have less resistance to blood flow and would provide more blood than small ones (Berne and Levy, 1977). While rat ACA-MCA collaterals are 4-5 times the number for human where interarterial junctions range in size from 200 to $600 \mu \mathrm{m}$ in diameter (vander Eecken and Adams, 1953), the outcome after rat MCA occlusion is unknown. Experimental studies seem justified on the premise that numerous junctions exist that may provide a collateral circulation for protection against infarction. On the one hand, rat may be a meaningful model to investigate parameters governing a protective collateral circulation. If collateral expansion occurs following MCA occlusion, either rapid or slow, then sizes and/or numbers of the junctions or other architectural features of the dorsal collaterals should be altered. On the other hand, if an infarct occurs, interventions to improve collateral circulation could be tested that may also have application for human.

\section{ACKNOWLEDGMENTS}

P. G. Jones and G. I. Jokelainen provided invaluable technical expertise. T. Tem Have and M. A. Schork assisted with the statistical analysis. We are grateful to all. The Michigan Heart Association and NIH Heart and Lung Institute HL 18575 contributed support for this investigation.

\section{IITERATURE CITED}

Batson, H.C. (1963) An Introduction to Statistics in the Medical Sciences. Burgess, Minneapolis, pp. 16-18.

Beevor, C.E. (1907) 'The cerebral arterial supply. Brain, 30: $402-425$

Berne, R.M., and M.N. Levy (1977) Cardiovascular Physiology. C.V. Mosby, St. Louis, pp. 59-64.

Black, K.L., B.R. Culp, D. Madison, O.S. Randall, and W.F.M. Lands (1979) 'The protective effects of diet ary fish oil on focal cerebral infarction. Prostaglan. Med., 3:257-268.

Brown, J.O. (1966) 'The morphology of circulus arterious cerebri in rats. Anat. Rec., 156:99-106. 
Coyle, P. (1975) Arterial patterns of the rat rhinencephalon and related structures. Exp. Neurol., 49:671-690.

Coyle, P. (1976) Arterial and venous vessel patterns in rat septal structures. In: The Septal Nuclei. J.F. DeFrance, ed. Plenum Press, New York, pp. 133-146.

Coyle, P. (1978) Spatial features of the rat hippocampal vascular system. Exp. Neurol., 58:549-561.

Craigie, E.H. (1955) Vascular patterns of the developing nervous system. In: Biochemistry of the Developing Nervous System. H. Waelsch, ed. Academic Press, New York, pp. $28-51$

Duret, H. (1874) Recherches anatomiques sur la circulation de l'encephale. Arch. Phys. Norm. Path. Serie 2, 1:60-91.

Gillilan, L.A. (1974) Potential collateral circulation to the human cerebral cortex. Neurol., 24:941-948.

Gilliłan, L.A. (1976) Extra- and intra-cranial blood supply to brains of dog and cat. Am. J. Anat., 146:237-253.

Greene, E.C. (1935) Anatomy of the rat. Trans. Am. Phil. Soc. NS, 27:1-370.

Hudgins, W.R., and J.H. Garcia (1970) Transorbital approach to the middle cerebral artery of the squirrel monkey: A technique for experimental cerebral infarction applicable to ultrastructural studies. Stroke, 1:107-111.

Jokelainen, P.T., G.I. Jokelainen, and P. Coyle (1982) Nonrandom distribution of rat pial arteriolar sphincters. In: Cerebral Blood Flow: Effect of Nerves and Neurotransmitters. D.D. Heistad and M. Marcus, eds. Elsevier, New York (in press).
Kamijyo, Y., and J.H. Garcia (1975) Carotid arterial supply of feline brain. Stroke, 6:361-369.

Molinari, G.F., M.D. Moseley, and J.P. Luaurent (1974) Seg mental middle cerebral artery occlusion in primates: An experimental method requiring minimal surgery and anesthesia. Stroke, 5:334-339.

O'Brien, M.D., and A.G. Waltz (1973) Transorbital approach for occluding the middle cerebral artery without craniec tomy. Stroke, 4:201-206.

Rowan, R.A., and D.S. Maxwell (1981) Patterns of vascular sprouting in postnatal development of the cerebral cortex of the rat. Am. J. Anat., 160:247-255.

Van Den Bergh, R. (1969) The periventricular intracerebra blood supply. In: Research on the Cerebral Circulation, Third International Salzberg Conference. J.S. Meyer, H Lechner, and O. Eichhorn, eds. C.C. Thomas, Springfield, Illinois, pp. 52-65.

vander Eecken, H.M., and R.D. Adams (1953) The anatomy and functional significance of the meningeal arterial anastomoses of the human brain. J. Neuropathol. Exp Neurol., 12:132-157.

Wang, H.S., and W.D. Obrist (1976) Effect of oral papa verine on cerebral blood flow in normals: Evaluation by xenon-133 inhalation method. Biol. Psychiatry, 11 $217-225$.

Zeman, W., and W.D. Innes, eds. (1963) Craigie's Neuroanat omy of the Rat. Academic Press, New York/London, pp. $30-49$ 